\title{
Preparedness for Practice: Physiotherapists View on an Undergraduate Programme in KwaZulu-Natal, South Africa
}

\author{
Thayananthee Nadasan ${ }^{1} \&$ Verusia Chetty ${ }^{1}$ \\ ${ }^{1}$ Discipline of Physiotherapy, School of Health Sciences, University of KwaZulu-Natal, South Africa \\ Correspondence: Associate Professor Verusia Chetty Discipline of Physiotherapy, School of Health Sciences, \\ Westville Campus, University of KwaZulu-Natal, Private Bag X54001, Durban 4000, South Africa. Tel: \\ 27-317-4890-5279. E-mail: chettyve@ukzn.ac.za
}

Received: October 16, 2019 Accepted: November 13, 2019 Online Published: December 29, 2019

doi:10.5539/gjhs.v12n1p88 URL: https://doi.org/10.5539/gjhs.v12n1p88

\begin{abstract}
Background: Community service physiotherapists need to be fit for clinical practice while addressing the evolving socio-cultural and economic health care challenges that face South African health systems. The introduction of community service for health care professions over a decade ago influenced education at tertiary institutions. The rhetoric remains as to the preparedness of physiotherapists for service delivery in a demanding primary health care setting.
\end{abstract}

Objectives: The study explored perceptions of preparedness of physiotherapists for clinical practice in their community service year.

Method: A qualitative approach using semi-structured interviews were used to understand perceptions of preparedness for community service by professional physiotherapists.

Results: Thirty nine physiotherapists who graduated at a University in Kwazulu-Natal, South Africa were recruited using snowball sampling. Data was analysed using conventional content analysis and yielded four dominant themes i.e. (1) facilitators of preparedness for community service, (2) inhibitors to perceived preparedness for community service, (3) curriculum review and (4) personal impact of community service.

Conclusions: Although, physiotherapists believed that community service contributed to their confidence as professionals, graduates deemed that physiotherapy programmes need a curriculum that is geared toward specific South African needs such as primary health care. Physiotherapists also believed that the undergraduate curricula should address global health care needs to prepare the new generation of health care professionals for global significance.

Keywords: curriculum; clinical education; community service; physiotherapy, South Africa

\section{Introduction}

Higher education in South Africa has changed since the emancipation of the country from the apartheid regime. A necessary shift occurred in Governance including the health sector, the education sector and health education systems. Changes included rectifying the injustices of the past apartheid administration whilst offering inclusive education for the 'non-traditional student' from underserved, disenfranchised and under-resourced communities (Cross \& Carpentier, 2009). This cohort of South African learners included health science and medical students from various scholarly and learning backgrounds who were now expected to fit into a higher education culture that adopted a traditional colonial education system. Coupled with this arose the primary health care shift within the countries health care system. The restructure of health care embraced the ideology of a decentralized more community focused approach. It advocates for community involvement and preventative strategies to health promotion and subsequent care (Kautzky \& Tollman, 2008). Health science students were consequently required to assume a learning style that would adequately equip them with core competencies and clinical skills to meet the demands of the community they serve as professionals whilst dealing with South African higher education system conundrums. It is believed that health science curricula fall short of preparing their health science students to accommodate this change. The instruction remains stagnant and deeply rooted in a hierarchical system of health care (Frenk et al., 2010). Thus, there is urgent need for higher education institutions to review and realign their health science curricula to imbibe the shift that transcends national boundaries, as they are feeders and 
collaborators of health systems.

For the context of this paper, the focus is on community service and the contribution of an undergraduate physiotherapy programme offered at a tertiary institution in South Africa in preparing students who are fit for clinical practice. Community service was introduced into the South African public health care system for allied health professions in 2003. Physiotherapists who graduated subsequently had to complete a compulsory community service year before full registration with the Health Professions Council of South Africa. (Futter, 2003) Community service responds to the needs of the country and enforces a devolving of critical health care services into underserved areas (Gounden, 2002). It is a good response to the concurrent shift to a primary health care model of meeting the needs of clients at a more accessible setting within communities (Frehywot, Mullan, Payne, and Ross, 2010). However, the question arises as to the revision and redress within undergraduate curricula in addressing the shift in health care (Futter, 2003). The health care restructuring necessitates a curriculum shift to align learning outcomes toward community based and primary health care demands (Krause, Viljoen, Nel, \& Joubert, 2006). However, shortcomings in curricula are reported in South African studies (Mostert-Wentzel, Frantz, \& Van Rooijen, 2013a; Mostert-Wentzel, Frantz, \& Van Rooijen, 2013b).

Physiotherapists should possess clinical skills combined with additional competencies such as managerial skills, communication skills and adept professionalism in order to function as independent practitioners in the communities they serve (Talberg \& Scott, 2014; Krause et al., 2006). The perception of preparedness of physiotherapist who engage in community service is essential as it affects practice and behaviour. However, scarcity exists in literature regarding the perception of community service therapists to function as autonomous practitioners and the influence of undergraduate training in preparing them (Talberg \& Scott, 2014) especially in the province of KwaZulu-Natal. Although studies explored community service in other provinces (Talberg and Scott 2014; Mostert-Wentzel, Frantz, \& Van Rooijen, 2013a; Mostert-Wentzel, Frantz, \& Van Rooijen, 2013b) KwaZulu-Natal has its unique population dynamics, health care priorities, health care structures and undergraduate curriculum. Therefore, researchers believed it was imperative to get insight into the perspectives of graduates from a tertiary institution in KwaZulu-Natal into the undergraduate curriculum preparing them for practice in order to further influence curriculum at the institution.

\subsection{Problem Statement and Aim}

Physiotherapists embarking on their community service year need to have core graduate competencies that include not merely clinical skills and health knowledge but professionalism, managerial and communication skills as well as social accountability. Tertiary higher education institutions should offer holistic, contextual and feasible curricula to train such professionals who should be reformers, critical thinkers and co-creators of understanding and knowledge. Physiotherapists are health professionals who venture into community service placement following graduation from a South African higher education institution. These physiotherapists need to be prepared to practice autonomously and manage high patient loads whilst tackling various managerial duties concurrently. They should offer an interface between health care users and health care systems. Scarcity of literature exists on the preparedness for practice in the province of KwaZulu-Natal focusing on the influence and contribution of the undergraduate curricula. Therefore, the question in the current study arose whether the undergraduate physiotherapy programme at a tertiary institution in KwaZulu-Natal, South Africa adequately prepares physiotherapists for community service and independent clinical practice.

\section{Research Methodology}

The researchers used an explorative qualitative approach with semi-structured interviews to answer the research question. Ethical clearance was obtained from the University of KwaZulu-Natal (Ethical approval number: SHSEC019/15). A snowball sampling was used to recruit participants who graduated from the tertiary institution under study in the preceding five years. Thirty-nine physiotherapists consented to participate. No incentives were offered to participating therapists.

Data from the interviews were transcribed verbatim and verified by participants. Thereafter, the researchers used NVIVO and content analysis to reflect data (Ritchie \& Spencer, 2002). Themes and subthemes were derived and verified after lengthy discussion by the team of researchers. An academic expert in qualitative methodology facilitated consensus in deriving themes and sub-themes among the researchers. Methodological rigour was maintained by using member checking and the use of thick rich descriptions. Illustrative quotes are reflected using pseudonyms to maintain anonymity (Creswell \& Miller, 2000).

\section{Results}

Thirty-nine physiotherapists participated in the survey. All physiotherapists participating completed a compulsory 
community service year in the South African National public health sector. The demographic characteristics and community service geographical placement of therapists is described in table one.

Table 1. Biographical Data and rural placement characteristics $(\mathrm{N}=39)$

\begin{tabular}{|c|c|c|c|c|c|c|c|c|c|c|c|c|}
\hline \multirow{2}{*}{ Participants } & \multicolumn{2}{|c|}{ Gender } & \multicolumn{4}{|c|}{ Age group (years) } & \multicolumn{3}{|c|}{ Ethnic group } & \multicolumn{3}{|c|}{$\begin{array}{l}\text { Community service } \\
\text { geographic area }\end{array}$} \\
\hline & Male & Female & $22-25$ & $26-30$ & $<30$ & Black & White & Indian & $\begin{array}{l}\text { Mixed } \\
\text { race }\end{array}$ & Rural & Semi-rural & Urban \\
\hline $\begin{array}{l}\text { Community } \\
\text { service } \\
\text { therapists }\end{array}$ & 18 & 21 & 26 & 12 & 1 & 10 & 8 & 21 & 2 & 28 & 8 & 3 \\
\hline
\end{tabular}

Majority of the therapists where female. The community placement areas for the participants were predominantly found in rural settings in South Africa. Four themes and various subthemes emerged and is summarised in table two. The themes and sub-themes from the physiotherapists in the study are reflected below in Table 2 .

Table 2. Summary of themes and sub-themes

\begin{tabular}{ll}
\hline Themes & \multicolumn{1}{c}{ Sub-Themes } \\
\hline \multirow{2}{*}{ Facilitators of preparedness for community service } & Clinical supervisors' approach \\
& Clinical education framework \\
Assessment methods & Theoretical content \\
\hline & Students dynamics in clinical platforms \\
Inhibitors to perceived preparedness for community service & Structural and organisational barriers \\
\hline & Lack of clinical supervision \\
Curriculum review & Poor communication skills \\
\hline & Incongruences in curriculum design \\
& Coherence of curriculum \\
& Relevance of curriculum \\
\hline
\end{tabular}

Theme one facilitators of preparedness for community service with subthemes namely clinical supervisors' approach, clinical education framework, assessment methods and theoretical content. Selective illustrative quotes are included below.

Physiotherapists' believed that the supervisory support offered at an undergraduate level within the programme facilitated their feelings of preparedness for practice. Andiswa's quote reflects this feeling.

"We had excellent supervisory staff that enforced adequate training for community service" Andiswa

The clinical education framework within the undergraduate programme with exposure in second year to clinical settings, more hands-on clinical teaching in level three with students engaging with problem solving and client management and an advanced autonomy in level four influenced physiotherapists feelings of preparedness for community service clinical practice.

“Good exposure to patients from 2 nd year helped to improve my clinical skills such as patient rapport." Siyabonga 
"The shifting of time (referring to increasing time at clinical sites) from 2 nd year to 3 rd and 4th year clinical made it all sufficient enough for me to be exposed and to practice my physiotherapy skills" Ashvir

The undergraduate programme uses both theoretical and clinical approaches to the curriculum framework. The assessment includes Objective Structured Practical Examination (OSPE) as well a clinical examination of patient management based at clinical settings. Physiotherapists in our study commended these clinical examination approaches in readying them for community clinical practice.

"OSPEs are essential for practicals and the clinical exams also equipped us with the required skills" Sam

One of the therapists as reflected in the statement below believed that the theoretical content added to her grooming for clinical work in her community service year.

"Physiotherapy modules were good and prepared us enough for clinical sites" Anneline

Theme two inhibitors to perceived preparedness for community service and subthemes included students' dynamics in clinical platforms, structural and organisational barriers, lack of clinical supervision and poor communication skills. The poignant quotes are illustrated and described below.

The number of students versus clinical supervisors affected preparedness for clinical practice. Physiotherapists felt that the fewer students in a group led to greater attention on remaining students during clinical blocks that facilitated learning. The smaller numbers also enabled improved group dynamics and peer learning initiatives.

"The less students we had at a hospital, was better for us, we got more attention" Sandy

"A small clinical group helped with the ability to learn and brainstorm" Sandile

The structural and organisational barriers is highlighted in Kathryn's quote and reflects the challenges experienced by students who felt overworked and under pressure by graduate demands.

"It was difficult too because of our workload between clinicals, lectures, exams and research in final year" Kathryn

Some participants referred to lack of supervision by clinical facilitators as well as mentors during their community service year. They believed that the lack of supervision hindered their clinical practice. They felt abandoned in their community service year.

"I just feel like in some blocks we needed more guidance to help us treat patients" Sue

"I also would like if they didn't just dump us here (referring to community service placement), we mmm need someone to supervise or even mentor us." Wandile

Communication also posed a barrier to feelings of preparedness, as the physiotherapists felt like preparation during the undergraduate programme of indigenous languages would have influenced their clinical management of patients and community service.

"I wish we did Zulu that actually would have helped us in community service, our Zulu was so arb (arbitrary)." Revashni

The third theme curriculum review with subthemes namely incongruences in curriculum design; coherence of curriculum and relevance of curriculum. Some therapists' quotes are shown below and reflect the challenges students experienced with regard to the undergraduate curriculum. They believed that there were incongruencies that affected their learning and subsequently their preparedness for community service placement and practice. Participants felt that some modules were irrelevant and time consuming. Physiotherapists also believed that there was a gap in the undergraduate programme in addressing global health care and thus preparing them for the international vocational landscape.

"Like some modules are not even relevant" Annie

"The first-year modules can be combined" Siyabonga

"The isiZulu (language) module wasn't even for us" Siszwe

"I don't feel like I can work or am confident to work overseas. I don't feel like I have the knowledge about physiotherapy in other countries because it wasn't covered (referring to undergraduate programme)" Revashni

The fourth and final theme personal impact of community service included subthemes professionalism; managerial skills; confidence and collaborative team contribution. Select quotes are represented below. As is understood by the narratives of the physiotherapists their learning continued in their community service year. They felt more confident to practice and learned about teamwork and professionalism during the community placement. 


\section{"I learnt a lot in community service like time management and how to be punctual" Siyabonga}

"I became stronger and more confident in that year (referring to community service)" Tanya

"I kind of learnt a lot about working in the multidisciplinary team and learnt about the different roles (referring to team)" Ashvir

"I had to be on my own and had to be a good manager because people depended on me" Annie

\section{Discussion}

The paper explored the influence of an undergraduate physiotherapy programme on the perception of preparedness for community practice. Many of the past students who were now practicing as professional physiotherapists were of South African Black and South African Indian decent and this could be attributed to the University being a prior black institution that allowed admission of students of diverse cultural backgrounds prior to the apartheid governance (University of KwaZulu-Natal, 2019)

Exploration into causative facilitators and inhibitors to feelings of preparedness revealed an array of themes such as supervisors' approach, curriculum design as well as clinical education framework. Futter (2003) stated that for physiotherapists to be adequately prepared for community service the undergraduate programme should mimic the clinical demands within its curriculum framework. Community placement blocks structured into the undergraduate curriculum could offer a possible solution for preparing students for the 'real world' (Futter, 2003). Community based education addresses the need in higher education physiotherapy curricula toward primary health care in redressing the burden of rehabilitative care in the country (Krause, Viljoen, Nel, \& Joubert, 2006). The introduction of community based education and transformation toward social determinants within health curricula spanning the last 10 years is understood to impact positively on social awareness of health professionals such as physiotherapists (Mostert-Wentzel, Masenyetse, Dinat, Botha, Jonkers, \& Oosthuizen, 2012).

Physiotherapists identified facilitators to their perceived preparedness for practice in their community service year. They reported that the clinical supervisors approach within their undergraduate clinical training framework contributed to their preparedness for practice. In Ernstzen, Bitzer and Grimmer-Somers (2010) study the clinical teacher, as a 'role model' was a key contributor to optimal learning. They gleaned much knowledge and skill from observing the role model. The verbalisation of the thinking process when the clinical supervisors demonstrated clinical techniques enhanced students learning. A qualitative study into physiotherapy students' use of evidence-based practice highlighted the role and influence of clinical supervisors and how this influence can improve the learning and facilitate successful teaching and learning using evidence-based practice (Olsen, Bradley, Lomborg, \& Nortvedt, 2013).

Other facilitators to preparedness for community practice was the adequate coverage of theoretical content within the undergraduate curriculum. The therapists in this study also commended the structure of the clinical education platform and the level of learning outcomes for progressive year of study from level two to level four that was their exit level year (there was no clinical education platform in level 1 only theoretical modules). Clinical education is fundamental to developing physiotherapists who are fit for clinical and community practice. However, there is no ideal or gold standard for a clinical education framework for physiotherapy currently (Lekkas et al., 2007). Authors do suggest that development and implementation of a working model should include clinical impact evidence (Lekkas et al., 2007).

Additionally, physiotherapists in our study supposed that the assessment methods such as the Objective Structured Practical Examination (OSPE) [usually conducted to examine clinical skills taught during the undergraduate programme] and bedside examination at clinical sites were facilitators to them feeling prepared for independent clinical practice. Ernstzen, Bitzer and Grimmer-Somers (2010) in their qualitative study reported that focused structured clinical education approach contributes to clinical competence. Patient demonstrations and discussion around cases were also identified as strategies to improve clinical competencies. Still, more intensive review of the physiotherapy curriculum in our study context needs to be conducted to identify appropriate teaching strategies and learning platforms to train graduates who are fit for community based health care. The strategies informing assessment also need to be probed further in order to influence clinical curricula (Lekkas et al., 2007).

Physiotherapists reported inhibitors to their perceived preparedness for practice. These inhibitors included student dynamics in clinical platforms referring to the number of students supervised versus clinical supervisor, structural and organisational barriers alluding to the limited time and lack of staffing issues. A lack of clinical supervision and poor communication skills were also perceived barriers to clinical education during the undergraduate programme. A study investigating occupational therapists' perceptions of community service in a similar context highlighted that high workloads as well as communication difficulties led to feelings of anxiety among therapists. 
Occupational therapists in the study also felt that staff shortages and administrative duties affected their feelings of angst (Van Stormbroek \& Buchanan, 2016). Mostert-Wentzel, Frantz and Van Rooijen (2013b) reported similar findings in research conducted with community service therapists. Language, cultural barriers, resource limitations and lack of discipline specific supervision and inadequate coverage of certain skill sets posed barriers to clinical practice (Mostert-Wentzel, Frantz, \& Van Rooijen, 2013b).

The undergraduate physiotherapy curriculum necessitates redress as it emerged as having incongruencies in design, coherence and relevance. Students at an institution in Cape Town, South Africa felt prepared for clinical practice and this was attributed to the well aligned physiotherapy curriculum (Talberg \& Scott, 2014). Researchers suggest that integration of theory and clinical education is imperative for this alignment. The study however lacked insight into how the alignment occurred and authors suggest further research into the area of curriculum review (Talberg \& Scott, 2014). According to Mothabeng (2006) students, perceptions are neglected into pedagogic approaches within physiotherapy curricula. Pedagogic research involving students needs further inquiry within South African higher education curricula which will influence a dire need to transform programmes through a student centered approach to learning.

The final theme was the personal impact of community service including professionalism, managerial skills, confidence, and collaborative team contribution. Physiotherapists reported that their competencies improved in their community service year and they learnt to function optimally within the multidisciplinary team. Collaboration was hindered in Mostert-Wentzel, Frantz and Van Rooijen (2013b) study by lack of understanding of roles of physiotherapists. Language barriers further hindered the community integration and suggestions included learning some language phrases used by the community and working with interpreters. Similarly, to our study, team collaboration contributed to personal growth and helped therapists in decision-making. Physiotherapy students at a university in Cape Town lacked confidence when they began their clinical placement block but reported that their confidence improved through the clinical block and they felt prepared even as students participating in clinical practice (Talberg \& Scott, 2014). In Mostert-Wentzel, Frantz and Van Rooijen (2013b) paper community therapists similarly felt their confidence improved during community service. In a study by Ramklass (2009) exploring physiotherapists' perspectives of community practice in South Africa, therapists also believed that language and cultural variances among community and physiotherapists led to clinical practice challenges. Additional education in culture and language for students and clinical staff is considered essential to improve the clinical learning experiences of culturally and linguistically diverse health care students (Mikkonen, Kuivila, Tuomikoski, \& Kääriäinen, 2016). The curriculum can include these strategies by realigning content and learning outcomes incorporating vernacular local language in assessment and treatment approaches.

\section{Conclusion}

The undergraduate programmes offered to equip professionals for clinical practice need to address core competencies to develop graduates who are fit for practice. The demands on the current health science student is further exaggerated by 'static' undergraduate health science curricula (Frenk et al., 2010). Graduates in health professions such as physiotherapy need a curriculum that is geared toward specific South African needs such as primary health care. However, health science students need global relevance and the curricula should address global health to prepare the new generation of health care professionals (Fried et al., 2010). The paper explored preparedness of physiotherapists for clinical practice in community service. Physiotherapists believed that the undergraduate physiotherapy curriculum needed review to bridge gaps within its design to improve professional learning and clinical outcomes. Transformative learning in preparation of physiotherapy students to socialise them to core competencies such advocacy and leadership should be an immediate change within curriculum but will involve executive and stakeholder engagement (Frenk et al., 2010). Furthermore, interprofessional learning should be fundamental and a rapid move away from professional silos or tribalism is advocated so that health science students can function as team members and understand scope and role of practice prior to clinical placement and community service (Horton, 2010).

\section{Competing Interests Statement}

The authors declare that there are no competing or potential conflicts of interest.

\section{References}

Creswell, J. W., \& Miller, D. L. (2000). Determining validity in qualitative inquiry. Theory into practice, 39(3), 124-130. https://doi.org/10.1207/s15430421tip3903_2

Cross, M., \& Carpentier, C. (2009). 'New students' in South African higher education: institutional culture, student performance and the challenge of democratisation. Perspectives in Education, 27(1), 6-18. 
Ernstzen, D. V., Bitzer, E., \& Grimmer-Somers, K. (2010). Physiotherapy students' and clinical teachers' perspectives on best clinical teaching and learning practices: a qualitative study. South African Journal of Physiotherapy, 66(3), 25-31. https://doi.org/10.4102/sajp.v66i3.70

Frehywot, S., Mullan, F., Payne, P. W., \& Ross, H. (2010). Compulsory service programmes for recruiting health workers in remote and rural areas: do they work?. Bulletin of the World Health Organization, 88, 364-370. https://doi.org/10.2471/BLT.09.071605

Fried, L. P., Bentley, M. E., Buekens, P., Burke, D. S., Frenk, J. J., Klag, M. J., \& Spencer, H. C. (2010). Global health is public health. The Lancet, 375(9714), 535-537. https://doi.org/10.1016/S0140-6736(10)60203-6

Frenk, J., Chen, L., Bhutta, Z. A., Cohen, J., Crisp, N., Evans, T., ... \& Kistnasamy, B. (2010). Health professionals for a new century: transforming education to strengthen health systems in an interdependent world. The lancet, 376(9756), 1923-1958. https://doi.org/10.1016/S0140-6736(10)61854-5

Futter, M. J. (2003). Developing a curriculum module to prepare students for community-based physiotherapy rehabilitation in South Africa. Physiotherapy, 89(1), 13-24. https://doi.org/10.1016/S0031-9406(05)60665-7

Gounden, P. (2002). Community service for physiotherapists: guest editorial. South African Journal of Physiotherapy, 58(2). https://doi.org/10.4102/sajp.v58i2.115

Kautzky, K., \& Tollman, S. M. (2008). A perspective on primary health care in South Africa: Primary health care: In context. South African health review, 2008(1), 17-30.

Horton, R. (2010). A new epoch for health professionals' education. The Lancet, 376(9756), 1875-1877. https://doi.org/10.1016/S0140-6736(10)62008-9

Krause, M. W., Viljoen, M. J., Nel, M. M., \& Joubert, G. (2006). Development of a framework with specific reference to exit-level outcomes for the education and training of South African undergraduate physiotherapy students. Health policy, 77(1), 37-42. https://doi.org/10.1016/j.healthpol.2005.07.015

Lekkas, P., Larsen, T., Kumar, S., Grimmer, K., Nyland, L., Chipchase, L., ... \& Finch, J. (2007). No model of clinical education for physiotherapy students is superior to another: a systematic review. Australian Journal of Physiotherapy, 53(1), 19-28. https://doi.org/10.1016/S0004-9514(07)70058-2

Mikkonen, K., Elo, S., Kuivila, H. M., Tuomikoski, A. M., \& Kääriäinen, M. (2016). Culturally and linguistically diverse healthcare students' experiences of learning in a clinical environment: A systematic review of qualitative studies. International journal of nursing studies, 54, 173-187. https://doi.org/10.1016/j.ijnurstu.2015.06.004

Mostert-Wentzel, K., Frantz, J., \& Van Rooijen, T. (2013). Status of undergraduate community-based and public health physiotherapy education in South Africa. South African Journal of Physiotherapy, 69(1). https://doi.org/10.4102/sajp.v69i1.369

Mostert-Wentzel, K., Frantz, J., \& Van Rooijen, A. J. (2013). A model for community physiotherapy from the perspective of newly graduated physiotherapists as a guide to curriculum revision. African Journal of Health Professions Education, 5(1), 19-25. https://doi.org/10.7196/ajhpe.203

Mostert-Wentzel, K., Masenyetse, L. J., Dinat, N., Botha, A., Jonkers, L. D., \& Oosthuizen, L. C. (2012). Involvement in and views on social responsibility of Gauteng members of the South African Society of Physiotherapy: A cross-sectional survey. South African Journal of Physiotherapy, 68(1), 22-28. https://doi.org/10.4102/sajp.v68i1.5

Mothabeng, D. J. (2006). An analysis of pedagogic research in physiotherapy education. South African Journal of Physiotherapy, 62(1), 14-18. https://doi.org/10.4102/sajp.v62i1.146

Olsen, N. R., Bradley, P., Lomborg, K., \& Nortvedt, M. W. (2013). Evidence based practice in clinical physiotherapy education: a qualitative interpretive description. BMC medical education, 13(1), 52. https://doi.org/10.1186/1472-6920-13-52

Ramklass, S. S. (2009). Physiotherapists in under-resourced South African communities reflect on practice. Health \& social care in the community, 17(5), 522-529. https://doi.org/10.1111/j.1365-2524.2009.00869.x

Ritchie, J., \& Spencer, L. (2002). Qualitative data analysis for applied policy research. In Analyzing qualitative data, 187-208. Routledge.

Talberg, H., \& Scott, D. (2014). Do physiotherapy students perceive that they are adequately prepared to enter clinical practice? An empirical study. African Journal of Health Professions Education, 6(1), 17-22. 
University of KwaZulu-Natal. Retrieved 13 November, 2019, from https://www.ukzn.ac.za/

van Stormbroek, K., \& Buchanan, H. (2016). Community Service Occupational Therapists: thriving or just surviving?. South African Journal of Occupational Therapy, 46(3), 63-72. https://doi.org/10.17159/23103833/2016/v46n3a11

\section{Copyrights}

Copyright for this article is retained by the author(s), with first publication rights granted to the journal.

This is an open-access article distributed under the terms and conditions of the Creative Commons Attribution license (http://creativecommons.org/licenses/by/4.0/). 